ARTICLE

DOI: $10.1057 /$ s41599-018-0075-y

\title{
Towards a manifesto for a critical digital humanities: critiquing the extractive capitalism of digital society
}

\author{
Mike Grimshaw ${ }^{1}$
}

\begin{abstract}
This article proceeds in two distinct parts. The first section engages with a deliberately small number of popular texts written by discriminating and interrogative consumers and producers of digital culture and society. While these may be dismissed as journalistic texts and sources by those of a more focused academic intent, here these texts are used because they are the connection between academic engagement and wider public readership. As such, they frame what can be termed the critical public engagement with digital capitalism. These texts are read in tandem with my thesis of immaterial capitalism and Marazzi's' The Violence of Financial Capitalism. The paper then concludes with what can be described as the 'manifesto turn' by raising some questions for a renewed engagement with digital society, to be undertaken from what is termed, an emergent critical digital humanities, as the site of critique and resistance. This is an exercise in what can be labelled Mongrel methodology and ideology, a neo-logism deliberately provocative in intent to signal a postacademic approach, chosen over such traditional descriptors as mixed-methods or assemblage and the like. As such, it may draw on Marxist thought but is not Marxist in ideology or final intent; it is critical of capitalism but acknowledges our on-going existence and possibilities within it; it is written by an academic seeking to act as intermediary between academic and non-academic readings and responses. It is a deliberate act of provocation as a manifesto call for change.
\end{abstract}

\footnotetext{
${ }^{1}$ University of Canterbury, Christchurch, New Zealand. Correspondence and requests for materials should be addressed to M.G. (email: michael.grimshaw@canterbury.ac.nz)
} 


\section{Setting the scene}

ver the past decade there have been an increasing number of popular texts, occupying that space between journalism and academia, written by discriminating and interrogative consumers and producers of digital culture and society. While these may be dismissed as journalistic texts and sources by those of a more focussed academic intent, I increasingly use these texts in my teaching and scholarship because they are the connection between academic engagement and wider public readership and most importantly, understanding. As such they frame what can be termed the critical public engagement with digital capitalism.

I want to begin this section with the text that ignited my interest in these questions regarding digital society and I wish to further begin with a framing statement that should be self-evident in its simplicity: digital society is digital capitalism. It does not matter in the end how we use the digital as much as how the digital uses us in various forms of extractive capitalism. This does not make me a Marxist (for what does that term really mean for most in the 21st century except for virtue-signalling nostalgia?) but rather one who is prepared to draw upon Marxist critiques and applies them non-dogmatically and in a deliberately nonorthodox fashion to this new environment in which we find ourselves. My concern is with what I term the Post-academic, the challenge of the intellectual to the discipline-specific and methodological and ideologically specific closed-circuits of much academic work and the universities. Too often we end up within smaller and smaller 'approved' academic processes and approaches that increasingly silo and balkanize academia and academic work. Yet at the same time that academia seemingly turns more and more inward we find ourselves within a discipline-busting expansion of information and possibilities via the capitalism masquerading as digital society. The Post-academic, in my conceptualization, is the self-proclaimed mongrel intellectual seeking a critical engagement with and within this new form of capitalism, unafraid to proudly mix and match a broad variety of sources and approaches, seeking new possibilities for critique. The term mongrel is deliberate in its challenge to the self-regard and self-disciplining of the academic from the societally-engaged position of the intellectual. For in their retreat in search of the approval of citation-indexes and 'impact factors', the academic increasingly only really serves the digital-matrix academic capitalism of the late modern university. (A warning: already I have coined the first of a number of possibly competing terms to describe varieties of modern capitalism; but this the deliberate approach of the mongrel intellectual who believes there is no singular experience nor normative term for contemporary capitalism; other possibilities will arise!).

\section{Critiquing digital society}

Andrew Keen's The Internet Is Not The Answer (2015) is the third in a series of critical investigations he undertakes critiquing what is occurring in our shift to a digital society. Keen (http://www. ajkeen.com) begins with a statement positioned against the utopian claims of digital society, noting that 'Rather than promoting economic fairness it is a central reason for the growing gulf between the rich and poor and the hollowing out of the middle classes' (Keen, 2015, p ix-x). Furthermore, the rise of digital society has resulted in an increase in the number of the poor, structural unemployment, the rise of monopolies, a panopticon of surveillance and the lack of transparency of big data, the rule of the mob, a misogynist on-line culture and a 'selfie-centred culture of voyeurism and narcissism', resulting in an online culture that is anti-diversity and enriching a tiny group of predominantly young white men (Keen, 2015, p x).
Keen is especially concerned with the rise of monopolies that concentrate wealth rather than spread it, monopolies such as Facebook, Google, Apple and Amazon. Because, as also discussed by Jonathan Taplin (http://www.jontaplin.com/), digital capitalism is not a free market but rather a monopolistic market. What we actually find ourselves within is a system of digital oligarchs and their clients that, as with other oligarchic systems, crosses over into politics (Taplin, 2017, p 4-5).

Central to all these monopolies is a radical reduction in a workforce to create profit compared to a non-digital, nonmonopoly economy. Keen quotes from a 2013 study by the US Institute of Local Self-Reliance that calculated Amazon destroyed a net 27,000 jobs in the American economy in 2012. Furthermore, whereas a traditional business would typically have 47 people employed to attain $\$ 10$ million in sales, Amazon, being a monopoly only need to employ 14 people to attain that 10 million (Keen, 2015, p 49). This is part of what I term the immaterial capitalism of web $3.0^{1}$ (that is data shared and re-used, being machine processed) comprised of Google, Facebook, Instagram, Tumbler, Youtube, Linkedin and the like. Here the focus is on the data produced by every user in every use, a combination of big data and data exhaust that has resulted in the creation of can be termed data factories that we all work for every time we go online. As Taplin observes, 'what we have been witnessing since 2005 is a massive relocation of revenue from creators of content to owners of platforms' (Taplin, 2017, p 102). As in the old factories of Fordist capitalism we are likewise alienated from capital. The difference with the Fordist factory is that now our labour is free and includes both our work and our leisure time. This is what I term the state of being beyond financial capitalism, finding ourselves instead in the new immaterial capitalism whereby we (often unknowingly) work for free every time we are on-line, especially in social media, 'manufacturing the very personal data that makes their companies so valuable' (Keen, 2015, p 57).

The global result of our shift online is two-fold: far fewer people are employed, especially in full-time work and far more wealth is being concentrated in far fewer hands. In what may seem (to many) to be a heretical point, this means the Occupy rallying call of the $99 \%$ against the $1 \%$ is unwittingly misguided, especially as so much of Occupy's opposition, organization, support, debate and celebration occurred via social media. This is not to say that we should not protest the bail-out of the banks by the state-especially given the bonus culture that then continued. Nor is this to excuse in anyway the inequality that the $1 \%$ signify. But in many ways the concentration on the $1 \%$ is to completely understate the contemporary situation and instead still find ourselves in the world signalled by Tom Wolfe's novel Bonfire of the Vanities (1987) and the self-styled Wall Street Masters of the Universe. Yet even in 2008 Wolfe noted that the Masters of the Universe had already left Wall Street and relocated to the hedge fund centre of Greenwich, Connecticut (Wolfe, 2008). Today, the reality is the concentration of power and money occurs in what can actually be termed the $0.0001 \%$ (Keen, 2015, p 202), a new monopoly oligarchy that somehow, in particular, the majority of western society seems to wish to work for and enrich for free. The deep irony is that the pervasive and uncritical use of social media by Occupy merely served to perpetuate the inequality that they protested against-yet as the $0.0001 \%$ signifies, the inequality is far more extreme than most realize. To understand what is occurring, Keen makes use of the term "creative destruction" which arises from Joseph Schumpeter's Capitalism, Socialism and Democracy (1996). Schumpeter observes, in an expression of capitalism as 'an evolutionary process' (Schumpeter, p 82), that 'this process of Creative Destruction is the essential fact about capitalism. It is what capitalism consists in and what every capitalist concern has got to live in' (Schumpeter, p 83). This is 
what Schumpeter terms 'the perennial gale' (Schumpeter, $\mathrm{p}$ 84) and which Keen borrows to reuse as 'the digital gale' (Keen, 2015, p 71) whereby 'Distributed capitalism equals ubiquitous capitalism' (Keen, 2015, p 72). To put this another way, Occupy Wall Street was protesting a form of capitalism that had actually transitioned into another form; the real power, money and inequality had radically relocated, but we saw these new digital companies as still primarily entrepreneurial, emancipatory and providing a new social network and cohesion. To be blunt, inequality was-and still often is-seen as the actions of 'men in suits'; but a capitalist is a capitalist whether in a suit or a t-shirt, whether in brogues or Birkenstocks. The digital economy is still a capitalist economy, it is just one that so many now have an affective engagement with and attachment to-without thinking just what occurs and is involved but this new 'creative destruction'.

\section{How to rethink this new capitalism}

Building on the work Swiss-Italian post-Fordist economist Christian Marazzi and his 2011 text The Violence of Financial Capitalism I argue that the violence of what I term immaterial capitalism occurs everywhere with increasingly little if any 'outside', especially with rise of crowd-sourcing. Marazzi's text tracks the shift from traditional capitalism to financial capitalism, a system whereby it is now money that is making money (as currency trading and various financial products), which is separate from the older system of a product-based economy. Such a shift occurs as part of post-industrial capitalism, which, via globalization, involves the relocation of much industrialization from western nations into emergent economies due to lower production and labour costs. As this occurs, we also experienced the development of a new form of capitalism based on speculation and investment, that also sees a shift in economic and political power from industrial capitalists and institutions to a new power based in financiers and financial institutions. Financialization involves stocks (that is, equities and shares), derivatives (based in contracts as cash flows concerning conditions of payments) and debts (in the forms of mortgages and bonds). Because of the level of capitalization required, the finance economy is really a credit and debit economy (Marazzi, p 27) wherein profits are made by not only extending credit and calling in debt but also by engaging in derivatives on these activities and so financial capitalism is a credit and debit form of capitalism. As Marazzi notes, financialization is the attempt 'to recover what capital could no longer get in the real economy in financial markets' (Marazzi, p 26). In this financialization we overwhelmingly exist as indebted consumers holding various combinations of credit card debt, hire-purchase agreements, mortgages and student loans (these being for most of us our level of participation) within the centrality of credit and debit-and this is whereby both consumption and profits occur. The activity for this capitalism is the financial markets that exist via computerization. ${ }^{2}$ As Finance is 'cosubstantial with the very production of goods and services' (Marazzi, p 28), this means, in my reading of the situation, that financial capitalism is what we continue with, even if we think it is 'just' capitalism. In other words, finance is a type of virtual capitalism that exists in the digital circulation of profit and loss. I label it virtual capitalism because for most of us this is a capitalism we do not 'see' in action (in comparison to industrial capitalism-or we could call it commodity capitalism - that makes 'things'), but we do certainly feel and see its effects, for it enables what we experience as daily capitalism. This is because Financial capitalism (as virtual capitalism) allows us, via credit and debit, to participate in daily life at the levels of both production and consumption. What we see with financialization is a shift to 'the new process of value production
(Marazzi, p 48). In my opinion, such a shift requires a new way of thinking and naming because we need to be able to recognize and signal the change that has occurred. Otherwise we run the risk of continuing to talk and think as if nothing has really changed. As will become evident I do not believe that any singular renaming is adequate to totally encompass the situation we find ourselves within. Therefore, a number of differing names for this new capitalism will be used, each responding to differing experiences. Yet if I was forced to reduce all these names to a single, simple definition then I would term this shift immaterial capitalism, involving no longer a return to the creation of making things, but rather a value production that Marazzi observes occurs from 'the sector of immaterial activities...all those creative, innovative activities with high value added' (Marazzi, p 47). My creation of the neologism immaterial capitalism arises out Marazzi's use of the autonomia Marxist terms 'immaterial labour' and 'immaterial activities'. For it is these terms that started me thinking about digital society and the type of activity, labour and capitalism that exist within it and that it supports.

In recent examples of immaterial capitalism, the rise of airbnb and uber turn private space into capitalist space, but in the process destroy thousands of service jobs both directly and indirectly. There is the same issue with digital images on both cameras and phones that saw the collapse of Kodak and up to 50,000 jobs (Keen, 2015, p 79). This hollowing out of jobs means the digital economy is what can be termed a donut economy with a big hole in the middle, because internet companies have very few employees compared to non-digital ones. But not only is digital society destroying jobs, the destruction of these jobs creates an even larger inequality that makes the gap of the divide larger, especially in mid-level jobs and the creation of what can be termed a digital feudal economy, a term that has quickly crossed from academic circles into wider critical digital society (for example, see Meinrath et al., 2011; Marr, 2016). Here I am reminded of Taplin's description of Facebook and Google as 'the new colonial powers' (Taplin, 2017, p 144). What we tend to forget however, in this concentration on the destruction of jobs, is that there is also now the creation of a central distinction between a direct and an indirect workforce-or what can be termed a paid and an unpaid workforce and it is the paid that increasingly exploit the unpaid because of the immaterial work being done. I am aware that Trebor Scholz argues that 'Digital labour is everything but "immaterial"' (Scholz, 2017, p 6) but I wish to make a distinction between digital labour of a paid workforce and the extractive capitalism of data capitalism, an extractive capitalism that now extracts data from the raw commodity of humans. This is not to dismiss the very real concerns of paid digital labour, intern digital labour, part-time and piece-meal digital labour that includes what Scholz terms the 'concealed workforce' (Scholz, 2017, p 23). But what also happens is that we are shifting into what is termed an app economy (an extraction of data everexpanding through the ubiquity of apps) that provides very few jobs but incredible profits for a very small elite. As Scholz notes much of this is increasingly also a gendered workforce of women undertaking digital free-lancing (Scholz, 2017, p 44ff), a freelancing that requires personal investment and digital access maintenance to ensure possible participation. It is important to note that all the costs are borne by the worker, but their pay does not reflect this. In a similar manner to the rise of the intern, access to participation is increasingly predicated on having the financial and social capital to do so. It is a rich irony that in the digital economy we now see the increasing exploitation of the educated middle-class; the tragedy is that this is still primarily a gendered exploitation of educated, middle-class women. Similarly, with the rise of the app economy and the self-service economy, many of the jobs being replaced and/or outsourced are 
the jobs of low-waged women. The violence of immaterial capitalism is also a gendered violence in its effects.

The app economy is actually about buying access to the digital workers: for example, when Instagram was bought by Facebook for US $\$ 1$ billion it had only 13 full-time employees (Keen, 2015, p 102). This does not make sense unless we realize that the app economy, included within the digital economy of immaterial labour, is actually based on access to data, the data that everyone using an app freely provides, the data that all users of digital society freely provide. Yet in providing the data that is in itself the valuable intelligence and is what is actually paid for by digital advertisers and creates such huge profits for such a small group of data harvesters, we the providers of the data, we the workers, are paid nothing. As Keen states: 'we work for free in the data factory' (Keen, 2015, p 115). The data is valuable to advertisers and this is where the profit is in social media: selling data to advertisers. The aim is simple: get people to freely give you data, use apps to give you direct, tailored access to them and so receive in return free, tailored data-including increasingly, claiming rights to the images taken and posted. Therefore this 'creates a surreal economy in which we are not only the creator of the networked product, but also the product itself (Keen, 2015, p 117). In short, we all work in a data factory whereby we labour to provide data that is sold without our consent to advertisers who use this to target us to consume more. The other violence undertaken within digital society is the destruction of thousands of jobs in recorded music, movies, publishing and photography. This occurs as part of what Taplin has observed: 'What we have been witnessing since 2005 is a massive relocation of revenue from creators of content to owners of platforms.' (Taplin, 2017, p 102). In effect, in digital society intellectual property has disappeared as a relevant or valid concept for most users and with it the collapse of copyright intensive jobs and industries. The result is what Keen terms 'a gift economy' (Keen, 2015, p 142) whereby the only profits of what is gifted onto the internet are gained by the 'tiny group of increasingly monopolistic internet companies' (Keen, 2015, p 142). Combined with the rise and dominance of predictive algorithms, what we see is the reduction of diversity and the situation whereby most creativity on the internet occurs in the hope of gaining exposure, or as Keen pithily notes: 'on the internet, most of us are perpetual interns' (Keen, 2015, p 193). The issue with intern culture on-line is the issue with intern culture off-line; that is there is a central divide whereby the intern is overwhelmingly the well-off who can afford to be an intern, in short, the one who can afford to work for free or for a bare minimum and the rest, the non-interns are increasingly sharecroppers caught up in a debt cycle of extraction and exploitation. Yet the real catch is that the intern is also a digital sharecropper (Carr, 2006) and this occurs in digital culture whereby we are told that being an intern is normal, expected and part of being entrepreneurial and so the internal ethos also resonates very well across onto the world of digital sharecropping. But this entrepreneurial economy, that first arose almost 25 years ago and is described as 'an economy where economic performance is related to distributed innovation and the emergence and growth of innovative ventures' (Thurik et al., 2013, p 303), is now also increasingly a piecemeal, intern-labour economy that is not really, in a digital environment, about 'working for yourself' or 'creating your own business'; rather it primarily involves working for free as a digital sharecropper.

Why should we be concerned? As consumers, the internet seems to be to our advantage. The reality however is that as citizens the internet creates a society of increasing inequality, a society of rapid job-loss and the reduction also in permanent work, and the control of our lives, our data and, via predictive algorithms, our choice, by monopolistic oligarchies. Digitally, we are all active workers as both producers and consumers, because our digital consumption is in itself data work because as Astra Taylor notes 'every click can be measured, every piece of data mined, every view marketed against' (Taylor, 2014, p 7). Digital society is really a society of advertising: data for advertising, advertising as data collection. The big shift was that of web 2.0 whereby ecommerce and social media combined with the aim of getting workers to create content without compensation. It is this that Nicholas Carr (http://www.nicholascarr.com/) in 2006 termed digital sharecropping; that is 'the distribution of production into the hands of the many and the concentration of the economic rewards into the hands of the few' (Carr, 2006). The worth of each individual bit of data is trivial, but the aggregation of this in data factories is where big profits are to be made. Digital culture is therefore a sharecropper culture, even in the realm of cultural production because of copying and piracy and the means of the control of access. What makes the digital sharecropping successful is that the vast majority of those working do not view their work as such, nor their data as valuable; in short we view it all as immaterial and so we participate in the violence of immaterial capitalism whereby all of our on-line life is a form of unpaid work within a monopoly, oligarchic capitalism. Furthermore, via the app economy, as noted, the monopolies are seeking to include our data within their monopolistic networks in a form of what can termed bottom-up control. That is, the oligarchic networks create or buy an app that on the one hand seems variously innocuous, useful, distracting, or entertaining but which most importantly creates an ever-expanding pool of free data to access. This ubiquity of apps means everyday life increasingly occurs within and via an ever-expanding pool of app options. The user of the app either does not know or does not care that their data is being extracted and immense profits are being made from this 'free' information. In many ways this is the ultimate triumph of the entrepreneurial economy, for our general lack of concern occurs within a culture focused increasingly on entrepreneurial success and the pursuit of the 'good idea' and personal profit.

Also of concern, especially with the rise of predictive search engines whereby we are told what to think, what to question and what to ask, is the filter bubble ${ }^{3}$ imposed upon us that predetermines for us what is made available and cuts off other options. This is not even consumer choice but is rather consumer direction driven by the pursuit of profit whereby immaterial capitalism is a targeted operation at each on-line individual driven by what Google calls the three-dimensional profile: the knowledge person-our search and click-steam, data; the social person-who we communicate and connect with; and the embodied person whereby our devices reveal where we are (Taylor, 2014, p 131). This is a totalitarian ethos immaterial capitalism targeted at material beings.

As Astra Taylor discusses, digital society has seen an increase in data profiling that is not only concerned with content and advertising but also includes the evaluating of data for credit and loan information and also price-variation for in-line shopping. The centrality of data also sees a turn to sponsored content, payola and product placement, sponsored tweets and blog posts and the unpaid marketing of your endorsement appearing on a friend's page. This means that all of digital life is increasingly turned into not only data harvesting but also a world of advertising (Taylor, 2014, pp 191-193). This is what Trebor Scholz labels 'the violence of participation' because our participation is not entirely voluntary. We suffer not only data mining but also, increasingly we suffer a 'personal and professional price' because refusal to access and use 'mainstream social media services... would be tantamount to social isolation' (Scholz, 2013, p x). The violence is therefore also a violence of the social, what can be termed the violence of digital ontology. That is, if I refuse to participate in social media, 
do I effectively cease to exist for what could be my social and professional/work networks? This becomes even more problematic with the cross-over of social media into professional/work life whereby organizations increasingly expect social media participation from their employees.

In all of this the central question is that of who profits and to what degree-and here occurs the violence, a violence wherein digital society is both the opiate and the means of exploitation. We digitally work for our social existence and our social identity but in the process create huge profits for that tiny minority who create the totalitarian, exploitative, monopoly architecture. This is because every on-line action and activity is the creation of monetizable information that is harvested, collated and sold to advertisers and behaviour market vendors such as Bluekai, Targusinfo, Neustar and Acxiom. In this a double exploitation occurs: on the one hand the manufacture of digital devices in large-scale low wage workshops in East Asia and then what can be termed the exploitation of the exploiters-the data harvesting of the users. In an increasingly globalized totalitarian system, the oligarchic monopolies exploit almost everyone for very low or no wages.

This is the latest expression of what Italian autonomist Marxists in the 1970s were terming the social factory, where work shifts from factory to society, where all of life becomes work (Terranova, 2013, pp 33-34) understood by the term immaterial labour. The difference between immaterial labour and what I term immaterial capitalism is that immaterial capitalism is dependent on digital farms, digital harvesting and digital sharecropping, undertaken against us without our consent or more often our knowledge, as part of a digital society demand to be online so as to participate and to digitally, increasingly socially, exist.

A central question is therefore one concerning the creation and control of the infrastructure of digital society. Digital society critic Evgeny Morozov asks do we wish Google to 'become the default provider of infrastructure-in health, education and everything else-for the twenty-first century?' (Morozov, p 55). This also occurs in open source software whereby the data increasingly goes back to Google despite the device or the platform, whereby immaterial capital is also data capitalism. As Morozov observes, 'this 'dataization' of everything is an extension of the much broader phenomenon of the financialization of everyday life' (Morozov, p 62) which also results in an ongoing, ever-changing manipulation of content. For when most data is controlled by Google or Facebook we have monopolistic control of our data and in effect, increasingly of every aspect of our lives, directly or indirectly; a data control that creates huge profits for a tiny minority. The issue is therefore clear: how do we get our data back? How do we stop the exploitation? Is it just about getting the digital monopolies to pay more tax or would that not change the central issue of 'the legal status of data'? (Morozov, p 65). A problem arises in that if everyone could be made a data entrepreneur then the financialization of life merely continues as we sell our lives as data; yet if we own our data but can't sell it would digital society as we know it continue to exist? So, we strike a central question: is the 'free access' the exploitative access, perhaps the Faustian bargain we pay to allow our data to be harvested and monopolized? Yet this Faustain bargain is, as virtual-reality pioneer and digital society critic Jaron Lanier (http://www.jaronlanier.com/) observes, a situation whereby 'all those hundreds of millions of users of social networking sites [are] reducing themselves in order to use the services...' (Lanier, 2010, p 53); a reduction that he presents as both a spiritual and behavioural failure that reduces our humanity. To put it in classical Marxist terms, this is a failure arising from our participation in a false consciousness in which free data exploits us in the name of a false consciousness of freedom, access and consumer choice, using free data as the social connection.
At the heart of this failure is what can be termed a distractive capitalism of false consciousness that is actually at heart a feudal capitalism in that it does not involve the creative destruction of Schumpeter, but rather the ongoing exploitation that shrinks the economy, shrinks jobs and results in a non-creative destruction that concentrates extreme levels of wealth and power into the hands of a very few. This is what Jarod Lanier calls 'the mistake of our age' (Rosenbaum, 2013), whereby digital networking is destroying the economy and hollowing out the middle class. Yet it would seem that most of us, increasingly distracted by digital capitalism and its products are either unaware, unconcerned or fear nothing can be done. It seems that digital society exists in state of being whereby as long as the access is available to me, as long as I can be connected, as long as I can consume, as long as I can socialize, I am unconcerned. Yet what we have is the retreat from material society into digital community (that is from the collective engagement and responsibility of society into the framed and inward looking self-interest of community) that sees us making the choice to increasingly self-limit our life to those with identical views, resulting in a type of digital gated community whereby as Keen observes 'the whole conversation is mirrored in a way that is reassuringly familiar' (Keen, 2007, p 55). As previously noted, this occurs within the ever increasing role of predictive algorithms that determine the choices both available and made for an increasing percentage of the global population. The result within immaterial capitalism is a situation of what can be termed (and this is the last of my capitalism neo-logisms ${ }^{4}$ ) directed, predicted capitalism whereby for many, choice becomes effectively no choice; and increasingly cultural creation and consumption likewise becomes focused on the limitation and control of choice.

\section{A place to begin the resistance: a re-thought critical digital humanities?}

What I have so far discussed is the background for the beginnings of a manifesto for a new, critical digital humanities that responds to the excesses and issues of digjtal capitalism. A manifesto sets out an impassioned political and social argument that becomes the open call to possibility. The manifesto operates out of what Mary Ann Caws terms 'the manifesto moment' which is its positioning 'between what has been done and what will be done, between the accomplished and the potential, in a radical and energizing division,' (Caws, 2001) a moment of crisis expressing 'what it wants to oppose, to leave, to defend, to change.' (Caws, 2001). It is my belief that we have reached a moment of crisis in digital capitalism that requires a re-thought, critical digital humanities as the place to respond: a critical digital humanities that is truly interdisciplinary and even more so, a mongrel postacademic space that is bale to cross between the academic and non-academic. As such a critical digital humanities becomes a space where the new thinking and critiquing of digital capitalism can occur-and this includes the creation of new terms that seek to identify and critically engage with the various experiences of this new form of capitalism. If digital capitalism is the overall experience, the ways in which this overall experience impact upon us requires differing descriptive nouns that highlight the multiplicity of ways digital capitalism operates and impacts upon us.

As Marx noted, the next stage from interpreting the world is to change it. So where might we start to do so? My concern as an academic is that our current structure of traditional departments means that any critique of and opposition to digital capitalism tends to be diffusely scattered across departments and disciplines. This is problematic for academics, but also for students. We may have pockets of critique and opposition in differing locations, but this occurs as part of a wider discipline and departmental focus. 
But given the centrality of the digital and digital capitalism to our lives perhaps now it is time to already reimagine and reorient one of the newer disciplines, to change it from a functionalist approach of using the digital to politicizing it as the place of interdisciplinary interpretation and change. In what I propose, perhaps the most important emphasis is that of a transdisciplinary focus, for the silo effect in too many universities severely limits the possibility for an integrated, holistic approach and conversation. A critical engagement with digital society and digital capitalism cannot be left to individuals or pockets scattered in say, variously sociology, media studies, law, economics or other disciplines.

What does this mean for digital humanities? Firstly, we need to acknowledge the context digital humanities currently exists within-the context I have outlined. This is a context of exploitative, immaterial capitalism, a digitalization of life that acts us violence upon us. We need to remember that Social Media exists only secondly for the expansion and maintenance of digital society, it exists and is sustained to provide increased data; it is, in short, a means of extraction. Secondly, we need to theorize what digital society tells us.

My hypothesis is as follows. The rise of and demand for the 'the social' is evidence of two things. The first is the triumph of the mantra of neoliberalism, Margaret Thatcher's infamous statement from 1987 that 'there's no such thing as society. There are individual men and women and there are families' (Thatcher, 1987). As political theorist Wendy Brown has recently remarked not only was this 'a challenge to public provisioning and an encomium to individual responsibility. Its meaning and effect went much further, however, and also deeper into the culture, to reject every kind of justice except that delivered by the market.' (Brown, 2017). The attack upon the social that sits as a central element within neo-liberalism furthermore is an attack and dismissal of 'what binds us in ways that exceed personal ties, market exchange, or abstract citizenship. It [the social] is where we, as individuals or a nation, practice or fail to practice justice, decency, civility, and care beyond the codes of market instrumentalism and familialism. And it is where political equality, so essential to democracy, is made or unmade.' (Brown, 2017). ${ }^{5}$

Secondly, we are witnessing the failure of physical, material society to act as a true alternative to the global addiction to the digital social, a social that exists as the central element of the extractive violence of immaterial capitalism. Furthermore, the fact that so many are increasingly addicted to various digital communities signals a failure not only of off-line society, but also of off-line community. For we seem to not only want to disengage with off-line society, we also seem to increasingly prefer on-line community to off-line community. Do we actually prefer distractive data to real people? As a result, our normative existence, the basis of our self-identity increasingly transfers online alongside both our work and our entertainment and occurs as our self-exploitation. We then exist in what Nicholas Carr terms 'the shallows' (Carr, 2010), whereby digital capitalism, immaterial capitalism and digital society coalesce into a capitalism of the shallows wherein the inherent violence is also a violence done to our attention.

Is this the ultimate price paid for digital society? A price paid culturally and mentally. Carr is concerned at the end of deep reading, a shift in habit and concentration demanded by the attention-deficit nature of internet culture and society, a situation whereby deep reading 'has become a struggle' (Carr, 2010, p 6). This reduction in our ability to concentrate, a reduction in our ability to undertake deep reading as a basis for deep thinking is, I argue, the central question for a re-thought, critical digital humanities. For if digital humanities is to be worthy of the name humanities then it needs to enable, facilitate and in fact demand deep reading and in order to do so, also, deep writing. This can be done if we concentrate on quality over volume, on taking time rather than multitasking, and of primarily working, reading and writing without social media. But this re-turn to deep reading and writing is not enough in its own, for every discipline would dearly like to experience such an event amongst its students-and often, sadly, to see it also return and be maintained amongst its staff. Furthermore, I am not naïve enough to believe that this can currently occur outside of capitalism and we also need to note that the university acts as a powerhouse factory of capitalism. Therefore, however much I may position my critique as arising from seeking an alternative to capitalism, at the moment we find ourselves within a capitalist hegemony. The rejection of 'the shallows' (a 'shallows' that increasingly infiltrates the classroom in the university) means we need to ask whether digital humanities and in fact more widely, digital capitalism, can acknowledge and endorse expertise and quality and distinguish between the expert and the qualified, against the amateur and the unqualified? In short, I am calling for a critical digital humanities and a wider digital capitalism that recovers, facilitates and celebrates the deep over and against the tranny of the shallows, that undertakes a type of social contract and this has to begin with those, like us the knowledge workers, who have something to celebrate and protect. For if we do not call for an informed digital citizenship, if we do not attempt to limit our self-exploitation in the face of social media monopolies, if we do not create and support platforms whereby the professional and the amateur are distinguished then we knowledge workers in the university have given up our right to also exist as the conscience and critic of society. For the reductive destruction of digital society and immaterial capitalism is too often also a destruction of concentration, a violence done via what Carr labels 'the business of distraction' (Carr, 2010, p 157), a distraction undertaken by the distractive exploitative capitalism of social media whereby the central aim of the platform is to keep us permanently, incessantly distracted and freely, unwittingly, willingly exploited.

What does this mean for digital humanities and the university that it exists within? I argue that a re-thought critical digital humanities is actually the location for a counter-revolution whereby a different experience and type of digital society can occur: a culture of the deep and not the shallows, a society of deep reading and deep thought facilitated by the digital, a culture of concentration and not distraction, a society of informed, critical participation, critique and opposition. As stated, this is not the more commonly existing functionalist digital humanities whereby humanities (or social science) seek to make use of computational tools and methods. For as has been recently noted, it is hard to answer what the existing functionalist digital humanities has actually accomplished. This is because digital humanities has remained the application of functionalist tools to create information in line with managerial metrics with the result that it has not made significant contributions to knowledge. But then, neither should we expect it to do so in its current conceptualization and processes. Rather, as Tim Brennan curtly observes 'Rather than a revolution, the digital humanities is a wedge separating the humanities from its reason to exist-namely, to think against prevailing norms. $\mathrm{DH}$ instead brings the humanities over to the outlooks of those administrators and legislators with programs that, on the one hand, put a scientistic gloss on method and, on the other, create a framework for lucrative tech deals in classrooms with the promise of the vast automation of teaching. The "results" of DH, then, are not entirely illusory. They have turned many humanists into establishment curators and made critical thought a form of planned obsolescence.' (Brennan, 2017). 
Also, if we wish to critique digital capitalism, then the existing functionalist digital humanities are not the place to attempt this because 'Digital Humanities has played a leading role in the corporatist restructuring of the humanities' (Allington et al, 2016). The problem is therefore that which was promoted as a new discipline of emancipation has turned out to be nothing more than a tool for oppression.

However I do note that there are emerging critical voices ${ }^{6}$ from within digital humanities seeking to retain the critical edge afforded by the humanities, and these are more in line with what I term an emerging critical digital humanities.

At the very least critical digital humanities, as an undertaking of the university, should aim to facilitate a creative critical digital culture by the knowledgeable and the professional that holds out against the cult of the amateur. This means universities need to create a critical digital humanities whereby texts are not, as Carr notes of Google books 'a library of snippets' wherein 'the stripmining of "relevant content" replaces the slow evaluation of meaning' (Carr, p 201, 166). A critical digital humanities should be the place whereby the deep thought and the deep discussion of the digital, can occur within the wider aims of the emancipatory transformation of digital society and the informed critique of and critical engagement with digital capitalism. Critical digital humanities therefore includes a democratic participation with and from informed knowledge and deep thinking in a counternarrative to the violence of immaterial digital capitalism. Critical digital humanities should therefore be the site of critique, opposition and resistance to the rise and increasingly totalitarian demand of social media in our lives, our work and, more specifically, within the university. If, as Andrew Keen proclaimed, the internet is not the answer, then a critical digital humanities needs to begin by asking the questions whereby the internet and digital society are repositioned and reimagined. Moreover, if this is really to be critical digital humanities and not digital production then we need to take not only the sources, materials and methods from humanities, but also its core ethos of deep reading, deep writing and deep critique. And in order to be critical, critical digital humanities must also be digital hermeneutics, the hermeneutics of the digital from the deep perspectives of the humanities. A critical digital humanities must also operate as an open access platform of debate, critique, creation, participation and circulation, making use of creative commons for only then can it seek to position itself as truly critical of immaterial digital capitalism. This therefore requires universities to be open to hosting not only such a department but also such open access and creative commons ventures ${ }^{7}$

\section{Conclusion}

The internet is not the answer, but it is a tool; the question is what do we wish to use the tool to accomplish and who gets to use and control this? And more so, how do we attempt to do this with, at the very least, the limitation of violence? I am not so naïve to believe Capitalism will end any time soon, but capitalism is a human creation and activity and so it is a hermeneutic activity. Over the past decade we have already seen an emergent neosocialist/neo-communist turn in response to the 2008 financial crisis. ${ }^{8}$ The internet as is, is one possible answer as to how we wish to live and how we wish capitalism to be, but central to hermeneutics is the other interpretation and possibility. This is, I argue, a central task of critical digital humanities, a task of critique, resistance, emancipation and the creation of alternatives, hosted within universities who take seriously their 21st century role as conscience and critic of digital society. Digital workers of the word unite, we have nothing to lose but our data chains.
Received: 31 July 2017 Accepted: 30 January 2018

Published online: 27 February 2018

\section{Notes}

1 There are many (and competing) definitions of web 3.0 in circulation on the web (see alsohttp://www.novaspivack.com/technology/web-3-0-the-best-official-definitionimaginable, http://calacanis.com/2007/10/03/web-3-0-the-official-definition/, http:// interactions.acm.org/archive/view/september-october-2013/web-3.0-has-begun)

2 For a fascinating and accessible history of the computerization of finance; see:Kevin Rodgers, Why Aren't They Shouting? A Banker's Tale of Change, Computers and Future Catastrophe (Random House, 2016); for a critique of the world of high frequency trading see Michael Lewis, Flash Boys: A Wall Street Revolt (W.W. Norton, 2015).

3 The term 'filter bubble' was coined by Eli Pariser in 2011 in his critique of Google's alogorithms. It became a widespread term via his book The Filter Bubble. What the Internet is hiding from you. See also: https://www.ted.com/talks/ eli_pariser_beware_online_filter_bubbles

4 As noted, I realize I have coined a number of different ways to describe our current form of capitalism and that is deliberate because I feel that any existing singular term or description fails to properly account for what is happening. Therefore, each new term is not meant to be a singular, all-inclusive or comprehensive description, but rather seeks to identify a different way for us to think about and critique the capitalism we find ourselves within.

5 See also Wendy Brown, Undoing the Demos: Neoliberalism's Stealth Revolution (2015). 6 Of particular note is Miriam Poser (2015), The radical potential of the Digital Humanities: The most challenging computing problem is the interrogation of power http://blogs.lse.ac.uk/impactofsocialsciences/2015/08/12/the-radical-unrealizedpotential-of-digital-humanities/

7 I note that while my own university did have a digital humanities programme that was inching toward such a critical digital humanities it has suffered funding cutbacks primarily because a focus on a (traditional) functional digital humanities failed to attract the expected numbers of students.

8 For a recent response see Making Communism Hermeneutical. Reading Vattimo and Zabala, ed. S. Mazzini and O. Glyn-Williams (Springer 2017).

\section{References}

Allington D, Brouillette S and Golumbia D (2016) Neoliberal tools (and Archives): a political history of digital humanities. https://areviewofbooks.org/article/ neoliberal-tools-archives-political-history-digital-humanities/

Brennan, T (2017) The digital-humanities bust. The Chronicle of Higher Education. http://www.chronicle.com/article/The-Digital-Humanities-Bust/241424?key=m5UvP8_ex3VKbYi7dlXqQR6znYtM88bAiGE3wUAxno_kQtgV4FDVbW6vz hmPZR7tUzltU0d2aXJqNTBfcTl2SzU2XzJmV3lyVXI2UHRp dmlOcGpYTmV xRGlldw

Brown W (2017) Defending society. Public Books, 10 October 2017. http://www. publicbooks.org/defending-society/

Carr N (2006) Digital sharecropping. Rough Type http://www.roughtype.com/? $\mathrm{p}=634$

Carr N (2010) The shallows. WW Norton \& Company, New York

Caws, M-A (2001) Manifesto: a century of ISMS. University of Nebraska Press, Lincoln

Fumagalli A (2011) Twenty theses on contemporary capitalism, trans. sabrina ovan (cognitive biocapitalism). Angelaki 16(3):7-17

Grimshaw M (2017) Hermeneutic capitalism? Prologue-the death and the challenge. In: Mazzini S, Glyn-Williams O (eds) Making communism hermeneutical. Reading Vattimo and Zabala, Springer, Cham, pp 211-220

Keen A (2007) The cult of the amateur. Doubleday/Currency, New York

Keen A (2015) The Internet Is not The answer. Atlantic Books, London

Lanier J (2010) You are not a gadget. Alfred A. Knopf, New York

Marazzi C (2011) The violence of financial capitalism. Semiotext(e), Cambridge, MA

Marr B (2016) Are we heading for digital-feudalism in our big data world? Forbes. https://www.forbes.com/sites/bernardmarr/2016/07/26/is-this-the-scaryworld-our-tech-revolution-will-create/2/\#72ba6ca8b7d6

Marx K (2013) Capital. Wordsworth Editions Limited, Ware, Hertfordshire

Meinrath S, Losey J, Pickard V (2011) Digital feudalism: enclosures and erasurse from the digital rights management to the digital divide. CommLaw Conspectus 19(2):423-479

Morozov E (2015) Socialize the data centres! New Left Rev 91:45-68

Rosenbaum R (2013) What turned Jaron Lanier against the Web? Simthsonian. com. https://www.smithsonianmag.com/innovation/what-turned-jaronlanier-against-the-web-165260940/?all

Scholz T (2013) Why does digital labor matter now? In: Scholz T (ed) Digital labor, Routledge, Cambridge, UK, pp 1-9 
Scholz T (2017) Uberworked and underpaid. How workers are disrupting the digital economy. Polity, Cambridge, UK

Schumpeter J (1996) Capitalism, socialism \& democracy. Routledge, New York

Taplin J (2017) Move fast and break things. Little, Brown \& Company, New York

Taylor A (2014) The people's platform. Metropolitan Books/Henry Holt \& Company, New York

Terranova T (2013) Free Labor. In: Scholz T (ed) Digital labor, Routledge, Cambridge, UK, pp 33-57

Thatcher M (1987) Interview for woman's own (no such thing as society). http:// www.margaretthatcher.org/document/106689

Thurik AR, Stam E, Audretsch DB (2013) The rise of the entrepreneurial economy and the future of dynamic capitalism. Technovation 33:302-310

Vattimo G (2010) Weak communism? In: Douzinas C, Zizek S (eds) The idea of communism. Verso, London \& New York

Vattimo G, Zabala S (2011) Hermeneutic communism: from Heidegger to Marx. Columbia University Press, New York

Wolfe T (1987) The Bonfire of the Vanities. Farrar, Straus \& Giroux, New York

Wolfe T (2008) Greenwich Time. New York Times, 27 September. http://www. nytimes.com/2008/09/28/opinion/28wolfe.html

\section{Data Availability}

Data sharing not applicable to this article as no datasets were generated or analysed during the current study.

\section{Additional information}

Competing interests: The author declares no competing financial interests.

Reprints and permission information is available online at http://www.nature.com/ reprints

Publisher's note: Springer Nature remains neutral with regard to jurisdictional claims in published maps and institutional affiliations.

\begin{abstract}
cc (i) Open Access This article is licensed under a Creative Commons Attribution 4.0 International License, which permits use, sharing, adaptation, distribution and reproduction in any medium or format, as long as you give appropriate credit to the original author(s) and the source, provide a link to the Creative Commons license, and indicate if changes were made. The images or other third party material in this article are included in the article's Creative Commons license, unless indicated otherwise in a credit line to the material. If material is not included in the article's Creative Commons license and your intended use is not permitted by statutory regulation or exceeds the permitted use, you will need to obtain permission directly from the copyright holder. To view a copy of this license, visit http://creativecommons.org/ licenses/by/4.0/.
\end{abstract}

(C) The Author(s) 2018 